\title{
PIGF deficiency causes a phenotype overlapping with DOORS syndrome
}

Smrithi Salian ${ }^{1}$, Hind Benkerroum, ${ }^{1}$ Thi Tuyet Mai Nguyen ${ }^{1}$, Sheela Nampoothiri ${ }^{2}$, Taroh Kinoshita ${ }^{3}$, Têmis Maria Félix $^{4}$, Fiona Stewart ${ }^{5}$, Sanjay M Sisodiya ${ }^{6}$, Yoshiko Murakami $^{3}$, Philippe M. Campeau ${ }^{1}$

\author{
Affiliations \\ ${ }^{1}$ CHU Sainte-Justine Research Center, University of Montreal, Montreal, QC H3T 1C5, Canada \\ ${ }^{2}$ Pediatric Genetics, Amrita Institute of Medical Sciences \& Research Centre (AIMS), Kochi, 682041, India \\ ${ }^{3}$ Yabumoto Department of Intractable Disease Research, Research Institute for Microbial Diseases, Osaka University, \\ Suita, Osaka 565-0871, Japan \\ ${ }^{4}$ Child and Adolescent Health, Universidade Federal do Rio Grande do Sul, Porto Alegre, Brazil \\ ${ }^{5}$ Northern Ireland Regional Genetics Centre, Belfast, Northern Ireland, BT97AB \\ ${ }^{6}$ NIHR University College London Hospitals Biomedical Research Centre, UCL Queen Square Institute of Neurology, \\ Queen Square, London, WC1N 3BG, UK.
}

\section{Corresponding author}

Philippe M. Campeau

Department of Pediatrics

CHU Sainte-Justine Research Center,

University of Montreal,

3175, Côte-Sainte-Catherine

Montréal QC Canada H3T 1C5.

E-mail: p.campeau@umontreal.ca

\section{Acknowledgements}

The authors are grateful to both the families for their cooperation in this study. This work is supported by CIHR (Canadian Institutes of Health Research) and FRQS (Fonds de Recherche du Québec - Santé) awards to PMC. 


\begin{abstract}
DOORS syndrome is characterized by deafness, onychodystrophy, osteodystrophy, intellectual disability, and seizures. In this study, we report two unrelated families with two individuals with DOORS syndrome without deafness. Exome sequencing revealed a homozygous missense variant in PIGF (NM_173074.3:c.515C>G, p.Pro172Arg) in both. We demonstrate impaired glycosylphosphatidylinositol (GPI) biosynthesis through flow cytometry analysis. We thus describe the causal role of a novel disease gene, $P I G F$, in DOORS syndrome and highlight the overlap between this condition and GPI deficiency disorders. For each gene implicated in DOORS syndrome and/or inherited GPI deficiencies, there is considerable clinical variability so a high index of suspicion is warranted even though not all features are noted.
\end{abstract}

Keywords: DOORS syndrome; PIGF; Glycophosphatidylinositol deficiency; GPI-anchored protein

\title{
Declarations
}

Funding: This work is supported by CIHR (Canadian Institutes of Health Research) and FRQS (Fonds de Recherche du Québec - Santé) awards to PMC.

Conflict of Interest: We declare that the authors do not have any conflict of interest and all have read and approved the final manuscript.

Ethics approval: This study was approved by the CHU Sainte-Justine institutional review board.

Consent to participate: Written informed consent was taken.

Consent for publication: Consent for publication has been obtained.

Availability of data and material: Yes

Code availability: Not applicable 


\section{Introduction}

More than 150 proteins are anchored to the cell membrane through GPI. The synthesis of GPI from phosphatidylinositol involves several reactions, and GPI is then attached to nascent proteins. Phosphatidylinositol glycan anchor biosynthesis class F (MIM\# 600153) (PIGF) encodes a protein that is involved in the GPI biosynthesis (Inoue et al. 1993). Many variants have been identified in genes that function in the GPI biosynthesis leading to inherited GPI deficiencies (IGDs). The main characteristic features of IGDsareglobal developmentaldelay, intellectual disability, seizures, hypotonia, and facial dysmorphisms. Another rare multiple congenital anomaly syndrome with features overlapping with IGDs is DOORS syndrome which is characterized by Deafness, Onychodystrophy, Osteodystrophy, intellectual disability (previously called mental Retardation), and Seizures. We have previously reported the causal link between DOORS syndrome and TBC1D24 variants in half of the recruited patients (Campeau et al. 2014), and have reported individuals with phenotype overlapping DOORS syndrome who had IGDs (Alessandri et al. 2018; Murakami et al. 2019).

With a constant aim to identify the genetic basis of DOORS syndrome, here we report PIGF variants in two individuals with DOORS syndrome from unrelated families of Indian origin from the same geographic location. We have identified a biallelic variant in PIGF, which encodes a protein involved in GPI-anchor biosynthesis, shared by both the individuals. Additionally, we have shown a defective GPI biosynthesis due to variants in PIGF, further highlighting its importance in DOORS syndrome (Murakami et al. 2019).

\section{Individuals and methods:}

Individuals and exome sequencing, including Ethics Statement

This study was approved by the CHU Sainte-Justine institutional review board. Samples were collected from individuals and families after taking appropriate, written, informed consent. Detailed clinical presentations, magnetic resonance imaging (MRI) findings and family history were recorded. Trio exome sequencing and data analysis were carried out as described previously (Murakami et al. 2019).

\section{Rescue assays of GPI-APs on fibroblasts}

Lentiviruses generated using a pLenti-GIII-CMV plasmid carrying a wildtype (WT) PIGF (ABM, Richmond, BC, Canada) were produced in HEK293T cells with the presence of packaging plasmids pMD2.G and psPAX2 (Addgene), 
then were transduced into the individual fibroblasts and selected by Puromycin resistance. These cells, untransduced cells, and control cells were cultured and harvested at 80-90\% confluency, stained with FITC-conjugated mouse antihuman CD73 (BioLegend) for 1 hour on ice in the incubation buffer containing 0.5\% BSA, then fixed in $3.7 \%$ formaldehyde. The nonspecific binding was washed off before analyzing by a BD FACSCanto II system (BD Biosciences) followed by FlowJo software analysis. CD73 was reduced to 50\%, versus healthy controls.

\section{Western blot for CD73}

For western blot analysis, protein lysate from patient fibroblast, transduced fibroblast with a lentivirus expressing wildtype PIGF and control fibroblast were separated by electrophoresis on Mini-PROTEAN TGX Precast Protein Gel (Bio-Rad, catalog \#4569033), transferred to polyvinylidene difluoride membranes. The membrane was blocked with 5\% milk and incubated with primary antibody, mouse anti-CD73 monoclonal antibody (1:500; MyBioSource, catalog \#MBS668166) and mouse anti-GAPDH monoclonal antobody (1:5000; Santa Cruz Biotechnology and catalog \#SC47724). Horseradish peroxidase-conjugated goat anti-mouse IgG (1:10,000; Cell Signaling Technology, catalog \#7076) was used as secondary antibody. Clarity Western enhanced chemiluminescence (ECL) substrate (BIO-RAD, catalog \#361059) was used to detect the immunocomplexes.

\section{Functional analysisin knockout cells}

A construct encoding HA-tagged human PIGF cDNA and its mutant were subcloned into the thymidine-kinasepromoter-driven pTK vector. These constructs were transfected into PIGF-deficient CHO cells by electroporation. Co-transfection with a luciferase-expressing plasmid was used to monitor transfection efficiency. Restoration of GPIAPs were analyzed by FACS, staining cells with anti-CD59 and anti-CD55, anti-uPAR antibody. Levels of expressed wildtype and mutant HA-tagged PIGF in the transfected cells with the strong promoter-driven pME vector were

analyzed by Western blotting using an anti-HA antibody (MBL) and glyceraldehyde 3-phosphate dehydrogenase GAPDH for the loading controls. We also measured luciferase activity and confirmed comparable transfection efficiencies (data not shown).

\section{Results}


Phenotypic details (Figure 1, A-D and E-I) of both individuals are summarized in table 1 . Individual 1 has been previously described as individual 23 in our initial DOORS syndrome study(Campeau et al. 2014). In summary, individual 1 is a 14 years old male child born to a consanguineous parents. His sibling with a similar phenotype died at 1 year 9 months. On examination, his height was $149 \mathrm{~cm}\left(4^{\text {th }} \%\right.$ ile $)$, his weight was $45 \mathrm{~kg}\left(25^{\text {th }} \%\right.$ ile $)$ and head circumference was $55 \mathrm{~cm}\left(50^{\text {th }} \%\right.$ ile $)$. Developmental delay, severe intellectual disability, hypoplastic fingernails, toenails and terminal phalanges, delayed permanent dentition, small teeth, anteverted nares, low-set pinna, open mouth, and atrial septum defect were noted. The individual had generalized tonic-clonic seizures. He has refractory seizures which occur on a daily basis, and is currently treted with three antiepileptics (phenobarbitone, levitiracetam, clobazam). He has no effective speech, cannot express any of his needs and has no toilet control. He displays head banging and repetitive nonpurposeful rocking movements of head. He also has precocious puberty (sexual maturity rating stage 4, testicular volume of $20 \mathrm{ml}$ bilaterally). Alkaline phosphatase, sometimes decreased or increased in GPI biosynthesis defects, was normal.

Individual 2 is a 13-month-old female child, the second child of third-degree consanguineous parents. There was no significant family history. She had a birth weight of $2.9 \mathrm{~kg}(-1 \mathrm{SD})$. Tonic posturing was noticed since birth, but no clear seizures. She has partial head control, does not reach for object nor does she look at faces. On examination, her weight was $7.25 \mathrm{~kg}(-2.83 \mathrm{SD})$, length was $74 \mathrm{~cm}(-0.3 \mathrm{SD})$, head circumference was $41.5 \mathrm{~cm}(-3.2 \mathrm{SD})$. Her anterior fontanelle was closed. Microstomia, micrognathia, coarse face and short nose were noted. She had hypoplastic convex nails on the thumb and the $5^{\text {th }}$ digit, bilateral triphalangeal thumbs, hypoplastic toenails from $1^{\text {st }}$ to $3^{\text {rd }}$ digit, a complete absence of toenails on $4^{\text {th }}$ and $5^{\text {th }}$ digit. Brainstem evoked response audiometry (BERA), MRI of brain and urine organic acids by gas chromatography-mass spectrometry (GC-MS) were normal. Alkaline phosphatase was normal. Exome sequencing revealed a homozygous c.515C $>\mathrm{G}$ (p.Pro172Arg) missense variant in a predicted transmembrane domain ofx/ PIGF (NM_173074.3) in both (see figure 1J). The variant was validated by Sanger sequencing in individuals and parents were found to be heterozygous carriers thus confirming a recessive mode of inheritance. $P I G F$ has never been associated with a genetic disease. This variant was not found in the gnomAD database nor in the GenomeAsia 100k database, lies at a highly conserved position and is predicted to be deleterious by multiple in silico prediction tools (CADD score of 27.6). Changing a proline for an arginine may affect the structure of PIGF given the conformation rigidity provided to protein backbones by proline. Membrane protein topology analysis using the 
SCAMPI tool on the TOPCONS server predicted that the mutation could affect which amino acids are incorporated in the membrane (Bernsel et al. 2008; Tsirigos et al. 2015).

To analyze the effect of the variant on the GPI-anchor protein (GPI-AP) biosynthesis, we performed flow cytometry for GPI-AP CD73 on fibroblast and rescue assay was also performed to demonstrate PIGF specificity. Transduction with a lentivirus expressing wildtype PIGF totally restored CD73 expression in the individual cells (Figure 1K). Western blot analysis of these cells suggests CD73 which does not get GPI-anchored becomes degraded (supplementary figure 1). Furthermore, functional analysis using PIGF deficient $\mathrm{CHO}$ cells demonstrated that the mutant had low residual activity compared to wildtype (Figure 1, L and M) while maintaining similar protein levels, thus suggesting an effect on the activity of the complex rather than an effect on PIGF protein stability.

\section{Discussion}

Here we describe two independent families where affected children had onychodystrophy, osteodystrophy, developmental delay and seizures associated with a homozygous c.515C $>\mathrm{G}$ variant in $P I G F$. Functional analysis by flow cytometry and rescue experiments highlight the importance of PIGF in GPI anchor biosynthesis. Although there is a phenotypic overlap between DOORS syndrome (usually caused by TBC1D24 variants) (Campeau et al. 2014) and inherited GPI deficiency, as can be illustrated by GPI biosynthesis variants in our initial DOORS syndrome cohort (see Supplementary Table 1) and the literature (Alessandri et al. 2018; Fleming et al. 2016; Murakami et al. 2019), a shared link between the underlying molecular pathways (TBC1D24 vesicular transport regulation and GPI biosynthesis) has yet to be determined. While 35\% of individuals with bi-allelic TBC1D24 have deafness (Balestrini et al. 2016), only 14\% of individuals with GPI biosynthesis defects do (Bellai-Dussault et al. 2019), which may help understand why deafness was not noted in the patients described here.

A PIGF partial deletion was previously observed in a child with "short stature with microcephaly and distinctive facies, OMIM \#615789". However, the deletion was heterozygous in the child as it was in the unaffected father, while there were bi-allelic variants in CRIPT in the child. Therefore, the article rightly concluded that mutations in CRIPT was responsible for the phenotype. Moreover, heterozygous loss-of-function carriers occur at an expected rate in the 
gnomAD population database (pLI score of 0 ), thus supporting the fact that haploinsufficiency for this allele is not deleterious (Karczewski et al. 2020).

Regarding the precise role of PIGF, a previous report has shown that disruption of Pig-o (phosphatidylinositol glycan anchor biosynthesis class $\mathrm{O}$ ) in $\mathrm{F} 9$ embryonal carcinoma cells resulted in the accumulation of a metabolite which was a GPI intermediate (Hong et al. 2000). The intermediate lacked phosphoethanolamine (EtNP) on the third mannose. Additionally, on the endoplasmic reticulum membrane (ER), PIGO and PIGF formed a complex and both proteins complemented the stability of each other. It was thus concluded that PIGF and PIGO function together in transferring EtNP to the third mannose in the GPI backbone. PIGO which forms a complex with PIGF degrades rapidly in the absence of PIGF (Shishioh et al. 2005). PIGF is also crucial for the stable expression PIGG (Hong et al. 2000). Furthermore, another study demonstrates that PIGF has functions beyond a structural role since (Stokes et al. 2014). In the present study, analysis of the effect of variant c.515C $>\mathrm{G}$ (p.Pro172Arg), on GPI-AP biosynthesis showed reduced levels of GPI-AP on the cell surface compared to control further suggesting its effect in GPI biosynthesis efficiency. Interesting future experiment would include studying the effect of the mutation on the stability and localization of PIGG and PIGO, and their interaction with PIGF.

With regards to the pathophysiology of the neurodevelopmental disease with epilepsy, this can be partly explained by the fact that several GPI-anchored proteins play key roles notably in embryogenesis, neurogenesis and synaptic specification (Lander et al. 1996; Martinelli and Fan 2007; Um and Ko 2017).

In conclusion, the phenotypic overlap between the two individuals and with inherited GPI deficiency disorders, in silico functional analysis and flow cytometer analysis, strongly suggest the pathogenicity of the PIGF variants identified in this DOORS syndrome cohort.

\section{Conflict of interest statement}

On behalf of all authors, the corresponding author states that there is no conflict of interest.

\section{References}

Alessandri J-L, Gordon CT, Jacquemont M-L, Gruchy N, Ajeawung NF, Benoist G, Oufadem M, Chebil A, Duffourd Y, Dumont C, Gérard M, Kuentz P, Jouan T, Filippini F, Nguyen TTM, Alibeu O, Bole-Feysot C, Nitschké P, Omarjee A, Ramful D, Randrianaivo H, Doray B, Faivre L, Amiel J, Campeau PM, 
Thevenon J (2018) Recessive loss of function PIGN alleles, including an intragenic deletion with founder effect in La Réunion Island, in patients with Fryns syndrome. European Journal of Human Genetics 26: 340-349. doi: 10.1038/s41431-017-0087-x

Balestrini S, Milh M, Castiglioni C, Luthy K, Finelli MJ, Verstreken P, Cardon A, Strazisar BG, Holder JL, Jr., Lesca G, Mancardi MM, Poulat AL, Repetto GM, Banka S, Bilo L, Birkeland LE, Bosch F, Brockmann K, Cross JH, Doummar D, Felix TM, Giuliano F, Hori M, Huning I, Kayserili H, Kini U, Lees MM, Meenakshi G, Mewasingh L, Pagnamenta AT, Peluso S, Mey A, Rice GM, Rosenfeld JA, Taylor JC, Troester MM, Stanley CM, Ville D, Walkiewicz M, Falace A, Fassio A, Lemke JR, Biskup S, Tardif J, Ajeawung NF, Tolun A, Corbett M, Gecz J, Afawi Z, Howell KB, Oliver KL, Berkovic SF, Scheffer IE, de Falco FA, Oliver PL, Striano P, Zara F, Campeau PM, Sisodiya SM (2016) TBC1D24 genotypephenotype correlation: Epilepsies and other neurologic features. Neurology 87: 77-85. doi: 10.1212/WNL.0000000000002807

Bellai-Dussault K, Nguyen TTM, Baratang NV, Jimenez-Cruz DA, Campeau PM (2019) Clinical variability in inherited glycosylphosphatidylinositol deficiency disorders. Clin Genet 95: 112-121. doi: $10.1111 /$ cge.13425

Bernsel A, Viklund H, Falk J, Lindahl E, von Heijne G, Elofsson A (2008) Prediction of membrane-protein topology from first principles. Proc Natl Acad Sci U S A 105: 7177-81. doi: 10.1073/pnas.0711151105

Campeau PM, Kasperaviciute D, Lu JT, Burrage LC, Kim C, Hori M, Powell BR, Stewart F, Félix TM, van den Ende J, Wisniewska M, Kayserili H, Rump P, Nampoothiri S, Aftimos S, Mey A, Nair LDV, Begleiter ML, De Bie I, Meenakshi G, Murray ML, Repetto GM, Golabi M, Blair E, Male A, Giuliano F, Kariminejad A, Newman WG, Bhaskar SS, Dickerson JE, Kerr B, Banka S, Giltay JC, Wieczorek D, Tostevin A, Wiszniewska J, Cheung SW, Hennekam RC, Gibbs RA, Lee BH, Sisodiya SM (2014) The genetic basis of DOORS syndrome: an exome-sequencing study. The Lancet. Neurology 13: 44-58. doi: 10.1016/S1474-4422(13)70265-5

Fleming L, Lemmon $M$, Beck $N$, Johnson $M, M u W$, Murdock $D$, Bodurtha J, Hoover-Fong J, Cohn R, Bosemani T, Barañano K, Hamosh A (2016) Genotype-phenotype correlation of congenital anomalies in multiple congenital anomalies hypotonia seizures syndrome (MCAHS1)/PIGNrelated epilepsy. Am J Med Genet A 170a: 77-86. doi: 10.1002/ajmg.a.37369

Hong Y, Maeda Y, Watanabe R, Inoue N, Ohishi K, Kinoshita T (2000) Requirement of PIG-F and PIG-O for Transferring Phosphoethanolamine to the Third Mannose in Glycosylphosphatidylinositol. Journal of Biological Chemistry 275: 20911-20919. doi: 10.1074/jbc.m001913200

Inoue N, Kinoshita T, Orii T, Takeda J (1993) Cloning of a human gene, PIG-F, a component of glycosylphosphatidylinositol anchor biosynthesis, by a novel expression cloning strategy. J Biol Chem 268: 6882-5.

Karczewski KJ, Francioli LC, Tiao G, Cummings BB, Alföldi J, Wang Q, Collins RL, Laricchia KM, Ganna A, Birnbaum DP, Gauthier LD, Brand H, Solomonson M, Watts NA, Rhodes D, Singer-Berk M, England EM, Seaby EG, Kosmicki JA, Walters RK, Tashman K, Farjoun Y, Banks E, Poterba T, Wang A, Seed C, Whiffin N, Chong JX, Samocha KE, Pierce-Hoffman E, Zappala Z, O'Donnell-Luria AH, Minikel EV, Weisburd B, Lek M, Ware JS, Vittal C, Armean IM, Bergelson L, Cibulskis K, Connolly KM, Covarrubias M, Donnelly S, Ferriera S, Gabriel S, Gentry J, Gupta N, Jeandet T, Kaplan D, Llanwarne C, Munshi R, Novod S, Petrillo N, Roazen D, Ruano-Rubio V, Saltzman A, Schleicher M, Soto J, Tibbetts K, Tolonen C, Wade G, Talkowski ME, Aguilar Salinas CA, Ahmad T, Albert CM, Ardissino $D$, Atzmon G, Barnard J, Beaugerie L, Benjamin EJ, Boehnke M, Bonnycastle LL, Bottinger EP, Bowden DW, Bown MJ, Chambers JC, Chan JC, Chasman D, Cho J, Chung MK, Cohen B, Correa A, Dabelea D, Daly MJ, Darbar D, Duggirala R, Dupuis J, Ellinor PT, Elosua R, Erdmann J, Esko T, Färkkilä M, Florez J, Franke A, Getz G, Glaser B, Glatt SJ, Goldstein D, Gonzalez C, Groop L, et al. 
(2020) The mutational constraint spectrum quantified from variation in 141,456 humans. Nature 581: 434-443. doi: 10.1038/s41586-020-2308-7

Lander AD, Stipp CS, Ivins JK (1996) The glypican family of heparan sulfate proteoglycans: major cellsurface proteoglycans of the developing nervous system. Perspect Dev Neurobiol 3: 347-58.

Martinelli DC, Fan CM (2007) The role of Gas1 in embryonic development and its implications for human disease. Cell Cycle 6: 2650-5.

Murakami Y, Nguyen TTM, Baratang N, Raju PK, Knaus A, Ellard S, Jones G, Lace B, Rousseau J, Ajeawung NF, Kamei A, Minase G, Akasaka M, Araya N, Koshimizu E, van den Ende J, Erger F, Altmüller J, Krumina Z, Strautmanis J, Inashkina I, Stavusis J, El-Gharbawy A, Sebastian J, Puri RD, Kulshrestha S, Verma IC, Maier EM, Haack TB, Israni A, Baptista J, Gunning A, Rosenfeld JA, Liu P, Joosten M, Rocha ME, Hashem MO, Aldhalaan HM, Alkuraya FS, Miyatake S, Matsumoto N, Krawitz PM, Rossignol E, Kinoshita T, Campeau PM (2019) Mutations in PIGB Cause an Inherited GPI Biosynthesis Defect with an Axonal Neuropathy and Metabolic Abnormality in Severe Cases. The American Journal of Human Genetics 105: 384-394. doi: 10.1016/j.ajhg.2019.05.019

Shishioh N, Hong Y, Ohishi K, Ashida H, Maeda Y, Kinoshita T (2005) GPI7 Is the Second Partner of PIG-F and Involved in Modification of Glycosylphosphatidylinositol. Journal of Biological Chemistry 280: 9728-9734. doi: 10.1074/jbc.m413755200

Stokes Matthew J, Murakami Y, Maeda Y, Kinoshita T, Morita Yasu S (2014) New insights into the functions of PIGF, a protein involved in the ethanolamine phosphate transfer steps of glycosylphosphatidylinositol biosynthesis. Biochemical Journal 463: 249-256. doi: 10.1042/bj20140541

Tsirigos KD, Peters C, Shu N, Kall L, Elofsson A (2015) The TOPCONS web server for consensus prediction of membrane protein topology and signal peptides. Nucleic Acids Res 43: W401-7. doi: 10.1093/nar/gkv485

Um JW, Ko J (2017) Neural Glycosylphosphatidylinositol-Anchored Proteins in Synaptic Specification. Trends in Cell Biology 27: 931-945. doi: 10.1016/j.tcb.2017.06.007 


\section{Figure legend}

Figure 1.Individual 1 (A) and 2 (E) have full lips and anteverted ear lobes, as well as hypoplastic fingers nails (B, C and F) and toes nail (D and G). (H-I) Radiographs of individual 2 show a triphalangeal thumb and brachytelephalangy (indicated by the arrow). (J). Schematic representation of PIGF protein, made with Protter. The affected amino acid lies in a transmembrane domain, after an alpha-helix. (K) Flow cytometry analysis of fibroblasts derived from individual 1 compared to healthy control. The individual cells were further transduced with lentiviruses expressing a wildtype PIGF cDNA. CD73 antibody was stained for GPI-AP.(L) Functional analysis of mutant PIGF cDNA (P172R). Flow cytometry analysis of GPI-APs in PIGF-deficient CHO cells transiently transfected with wildtype and mutant HA-tagged PIGF cDNAs subcloned in pTK vector. Note with the wildtype protein (red) the higher peak on the right. (M) Cell lysates from the transfected cells were used for western blot analysis using the HA tag antibody, thus confirming proper cDNA expression.

\section{Table}

Table 1. Summary of clinical, radiological, and biochemical findings in the affected individuals. 


\section{Supplementary data}

Supplementary table 1. Bi-allelic variants in GPI biosynthesis genes in the initial DOORS syndrome cohort.

Supplementary figure 1. Western blot analysis of CD73 in fibroblasts. 